\title{
DEVELOPMENT OF REGIONAL TSS ALGORITHM OVER PENANG USING MODIS TERRA (250 M) SURFACE REFLECTANCE PRODUCT
}

\author{
ABD RAHMAN MAT AMIN ${ }^{1 *}$, KHIRUDDIN ABDULLAH ${ }^{2}$, HWEE SAN LIM ${ }^{2}$, MUHD \\ FAUZI EMBONG ${ }^{1}$, FADHLI AHMAD ${ }^{3}$, ROSNAN YAACOB ${ }^{3}$
}

${ }^{1}$ Faculty of Applied Sciences, Universiti Teknologi MARA, Kampus Kuala Terengganu, 21080 Kuala Terengganu, Malaysia; e-mail:abdra401@tganu.uitm.edu.my

${ }^{2}$ School of Physics, Universiti Sains Malaysia, 11800 Minden, Pulau Pinang, Malaysia

${ }^{3}$ Universiti Malaysia Terengganu, 21030 Kuala Terengganu, Malaysia

${ }^{*}$ Author for correspondence

Abstract

Mat Amin A.R., Abdullah K., Lim H.S., Embong M.F., Ahmad F., Yaacob R.: Development of regional TSS algorithm over Penang using MODIS Terra $(250 \mathrm{~m})$ surface reflectance product. Ekológia (Bratislava), Vol. 35, No. 3, p. 289-294, 2016.

Total suspended sediment (TSS) plays a significant role in the environment. Many researchers show that TSS has a high correlation with the red portion of the visible light spectrum. The correlation is highly dependent on geography of the study area. The aim of this study was to develop specific algorithms utilizing corrected MODIS Terra 250-m surface reflectance (Rrs) product (MOD09) to map TSS over the Penang coastal area. Field measurements of TSS were performed during two cruise trips that were conducted on 8 December 2008 and 29 January 2010 over the Penang coastal area. The relationship between TSS and the surface reflectance of MOD09 was analysed using regression analysis. The developed algorithm showed that Rrs are highly correlated with the in-situ TSS with $\mathrm{R}^{2}$ is 0.838 . The result shows that the Rrs product could be used to estimate TSS over the Penang area.

Key words: TSS, MODIS, surface reflectance, Penang.

\section{Introduction}

The decline in water quality of coastal water, mainly caused by the total suspended sediment (TSS), has encouraged ocean researchers to develop several methods to measure the water quality. The methods could be classified into direct and indirect measurement. The common method used to measure TSS is field sampling. In this method, the water sample is collected and then filtered to extract TSS. The filtered material is then dried, weighted and divided by the sample value to obtain TSS. This method provides accurate and point based measurement, but spatial variations are rarely captured and temporal resolution is often limited (Curran, Novo, 1988; Miller, McKee, 2004; Pavelsky, Smith, 2009). The presence of remote 
sensing technology offers an alternative way of tracking spatial and temporal variations of TSS concentration. Utilizing remote sensing technology could reduce cost and save time. The use of remote sensing technology to estimate/map the TSS concentration is well documented. In this technique, researchers have used several wavelengths, and then related it to the field, measuring TSS.

The fact that TSS increases the radiant emerging from the surface waters in the visible and near infrared region of the electromagnet spectrum has been known since the late 1970's (Ritchie et al., 1976). A number of researchers concluded that the TSS concentration is found to be linear, and there is a curvilinear relationship between TSS and radiance or reflectance at green $(500 \mathrm{~nm})$ to red $(600 \mathrm{~nm})$ of the visible spectrum (Ritchie et al., 1976; Curran, Novo, 1988; Doxaran et al., 2003; Wang et al., 2009; Miller, McKee, 2004; Chu et al., 2009; Long, Pavelsky, 2013). The usage of the red portion of the electromagnetic spectrum over turbid water is well documented. Miller and McKee (2004) have found that the remote sensing reflectance (Rrs) of red channels of MODIS sensor could be successfully utilised to map TSS over turbid productive water. Additional evidence from other investigators shows that the red portion of the electromagnetic spectrum could be utilised to examine water quality parameter related to TSS (Hu et al., 2004; Chen et al., 2007; Rodriguez-Guzman, GilbesSantaella, 2009; Petus et al., 2010; Moreno-Madrinan et al., 2010).

To date, many researchers are interested to estimate TSS concentration utilizing remote sensing technique. To achieve this goal, they need to use both field and remote sensing data. Generally, they calibrate the remote sensing data with field data to develop an algorithm. Most of them have proposed a relationship between reflected solar radiance measured by airborne and satellite-based instruments with field measurement TSS in a wide range of inland and coastal waters. Miller and McKee (2004) have used the remote sensing reflectance of MODIS Aqua $250 \mathrm{~m}$ resolution to estimate TSS. Wang et al. (2010) have used MODIS Terra band 2 and band 5 to estimate TSS over the lower Yangtze River, China. Another researcher, Min et al. (2012), has developed an algorithm to monitor TSS variation over a Saemangeum coastal area of Korea using Landsat and MODIS data. Kuang et al. (2011) have used integrated techniques to monitor TSS transport over Nanhui shore. Villar et al. (2013) has conducted a study of TSS transport in the Madeira River, Brazil, using MODIS 250 m remote sensing images.

It is well known that the algorithms developed over different region differ due to the variations in the optical characteristic of the TSS, such as sediment types and particle size distribution (Miller, McKee, 2004). The main objective of this study was to develop specific algorithms utilizing MODIS Terra $(250 \mathrm{~m})$ surface reflectance product (MOD09) to map the TSS over the Penang coastal area. This study used the field measurement TSS that was obtained through two cruises that were conducted on December 2009 and January 2010.

\section{Study area}

This study was conducted over Penang Island, Malaysia. The study area is located within latitudes $5^{\circ} 12^{\prime} \mathrm{N}$ to $5^{\circ} 30^{\prime} \mathrm{N}$ and longitudes $100^{\circ} 09^{\prime} \mathrm{E}$ to $100^{\circ} 26^{\prime} \mathrm{E}$. This area is located at the north of Malaysia peninsular. The island covers an area of $298 \mathrm{~km}^{2}$. To the east of this island is the Malaysia Peninsular mainland. It is separated from the mainland by the Penang straits. It is connected to the mainland by two bridges. The constructions of Penang's first bridge started 
in 1982, and it officially opened on August 3, 1985. The total length of this bridge is $13.5 \mathrm{~km}$ and its length over water is $8.4 \mathrm{~km}$. It connects Perai (Mainland) to Gelugor (Penang Island). The construction of Penang's second bridge, which has a length of $16.9 \mathrm{~km}$ over water, started in November 2008, and it officially opened on March 1, 2014. It connects Batu Kawan (Mainland) to Batu Maung (Penang Island). The construction of the bridges could disturb the sea current flow over the Penang straits. So, it is considered important to keep monitoring the TSS concentration in this area. The location of the study area is shown in the Figure 1.
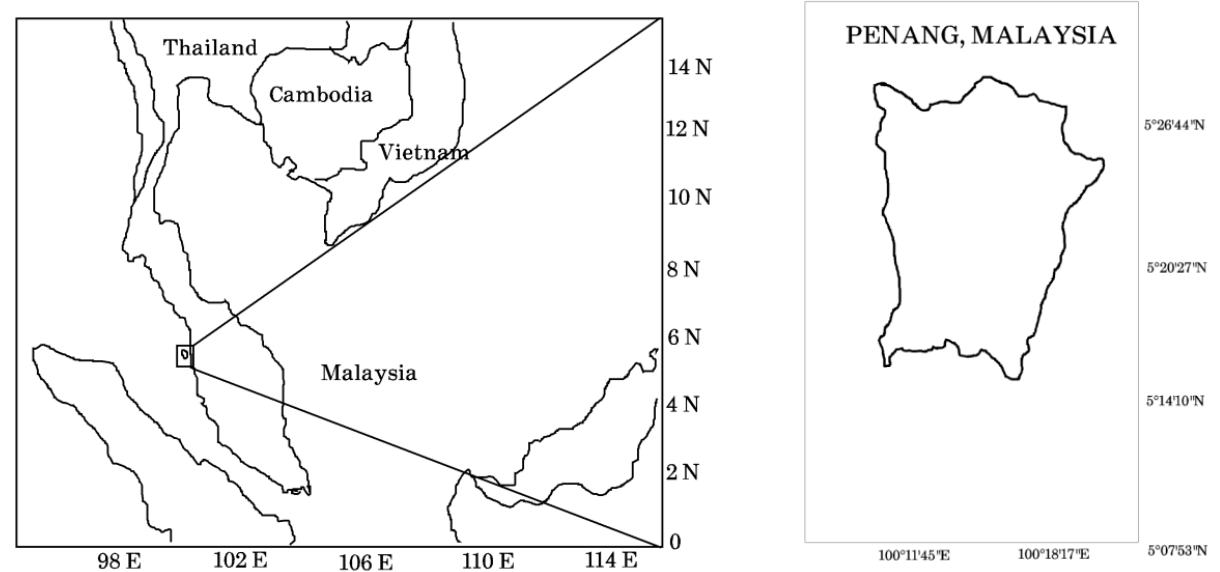

Fig. 1. Location of the study area.

\section{Data and methods}

\section{Fields sampling}

Two trips were conducted on 8 December 2009 and 29 January 2010. Only 8 TSS data points from the first trip and 11 TSS data points from the second trips could be used for analysis. A large part the data couldn't be used due to cloud contamination. The water samples were then analysed in laboratory to determine the TSS by using the standard method as suggested by another researcher.

\section{Remote sensing imagery}

MODIS daily surface reflectance product MOD09GQ was used in this study. This is a $250 \mathrm{~m}$ resolution product that consists of two bands: band 1 (red; $620-670 \mathrm{~nm}$ ) and band 2 (near-infrared; $841-876 \mathrm{~nm}$ ). The surface reflectance product was corrected for atmospheric gasses, aerosols and thin cirrus clouds using $6 \mathrm{~S}$ atmospheric algorithm (Kotchenova et al., 2006). This product could overcome the uncertainties in the atmospheric correction procedure. The data was distributed by the United States Geological Survey (USGS) and downloaded from Earth Explorer website (http://earthexplorer.usgs.gov). The data were used by another researcher to estimate TSS over the selected study area (Moreno-Madrinan et al., 2010; Long, Pavelsky, 2013).

\section{Processing method}

The downloaded data was processed using the ENVI 4.5 software. The data was then Geo-referenced to the Geographic Lat/Lon datum WGS 84. During this study, the two methods were analysed to be used for match-up comparison. The methods analysed were: single pixel and $3 \times 3$ pixels. In single pixel method, the station coordinate is directly matched with the associated pixel. The area covered by a single pixel is about $0.0625 \mathrm{~m}^{2}$ at nadir view. Mean- 
while, in $3 \times 3$ pixels method, nine MODIS surface reflectance were averaged to one single pixel. The coordinates of the station were located at the centre of the $3 \times 3$ selected pixels. The area covered by $3 \times 3$ pixels was about 0.5625 $\mathrm{m}^{2}$ at nadir view. The averaged surface reflectance was then inserted into the table. After that, a plot of the surface reflectance against the in situ TSS data was constructed.

\section{Results and discussion}

The relationship between surface reflectance and in-situ TSS was investigated by using regression analysis utilizing SigmaPlot 10. Table 1(a) shows the result of the regression for each date by using the single pixel method. The regression coefficient $\left(\mathrm{R}^{2}\right)$ for the data collected on 8 December 2009 was 0.589 . Meanwhile, $\mathrm{R}^{2}$ for the data collected on 29 January 2010 was 0.715 . The $\mathrm{R}^{2}$ for the combination of the data was 0.803 . Table $1(\mathrm{~b})$ shows the result of the $3 \times 3$ pixel method. The $\mathrm{R}^{2}$ for this method showed better result than single pixel method. The $\mathrm{R}^{2}$ value for the combination date was slightly better than the single pixel method. The value was given by 0.837 .

$\mathrm{T}$ a b l e 1. (a) Single pixel method; (b) $3 \times 3$ pixel method.

\begin{tabular}{|l|l|l|l|l|}
\hline Location & Date & No. of samples & Algorithm & R $^{2}$ \\
\hline Penang & 8 Dec. 2009 & 8 & TSS $=69199 \mathrm{R}^{2}-84770 \mathrm{R}+2687$ & 0.589 \\
\hline & 29 Jan. 2010 & 11 & TSS $=-5178 \mathrm{R}^{2}+1316 \mathrm{R}=29.60$ & 0.715 \\
\hline & Combined & 19 & TSS $=-4882 \mathrm{R}^{2}+1398 \mathrm{R}+27.09$ & 0.803 \\
\hline \multicolumn{7}{|l|}{ (a) } & Correlation \\
\hline Location & Date & No. of samples & Algorithm & 0.577 \\
\hline Penang & 8 Dec. 2009 & 8 & TSS $=-91104 \mathrm{R}^{2}+11840 \mathrm{R}-3741$ & 0.797 \\
\hline & 29 Jan. 2010 & 11 & TSS $=-9532 \mathrm{R}^{2}+1749 \mathrm{R}+18.29$ & 0.838 \\
\hline & Combined & 19 & TSS $=-11658 \mathrm{R}^{2}+2065 \mathrm{R}+10.93$ & \\
\hline
\end{tabular}

Figure 2 (a) and (b) show the plot of TSS against surface reflectance for 8 December 2009 and 29 January 2010 that were constructed using $3 \times 3$ pixel methods. Both plots are in polynomial form.
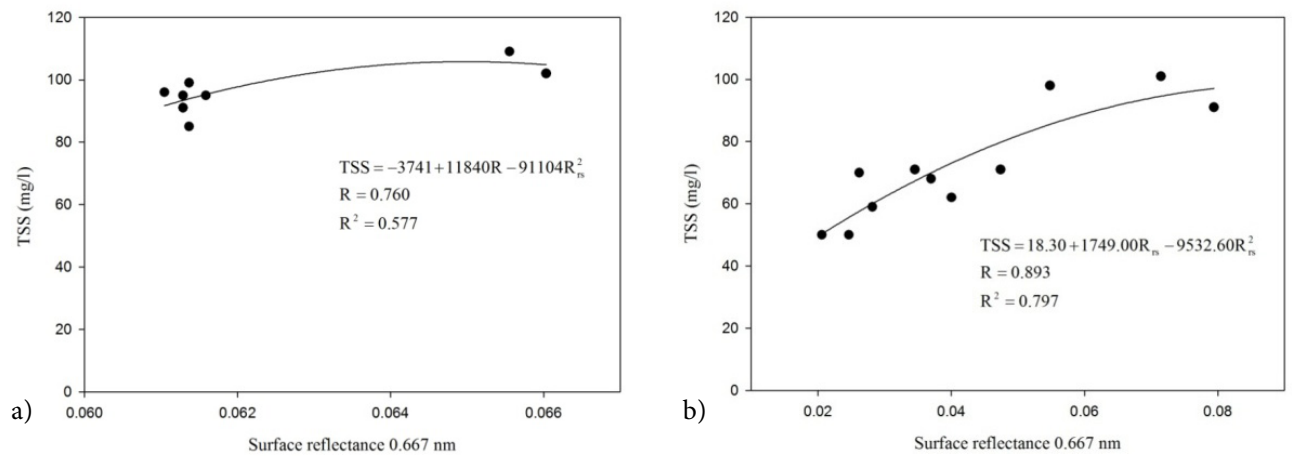

Fig. 2. (a) TSS against surface reflectance for the date of December 8, 2009, (b) TSS against surface reflectance for the date of January 29, 2010. 
Figure 3(a) represents the plot of TSS against Rrs for the combination data. This plot shows higher $\mathrm{R}^{2}$ value as compared to the single date data. $\mathrm{R}^{2}$ for this combination date is 0.8379. Figure 3(b) shows the plot of measured TSS against estimated TSS.
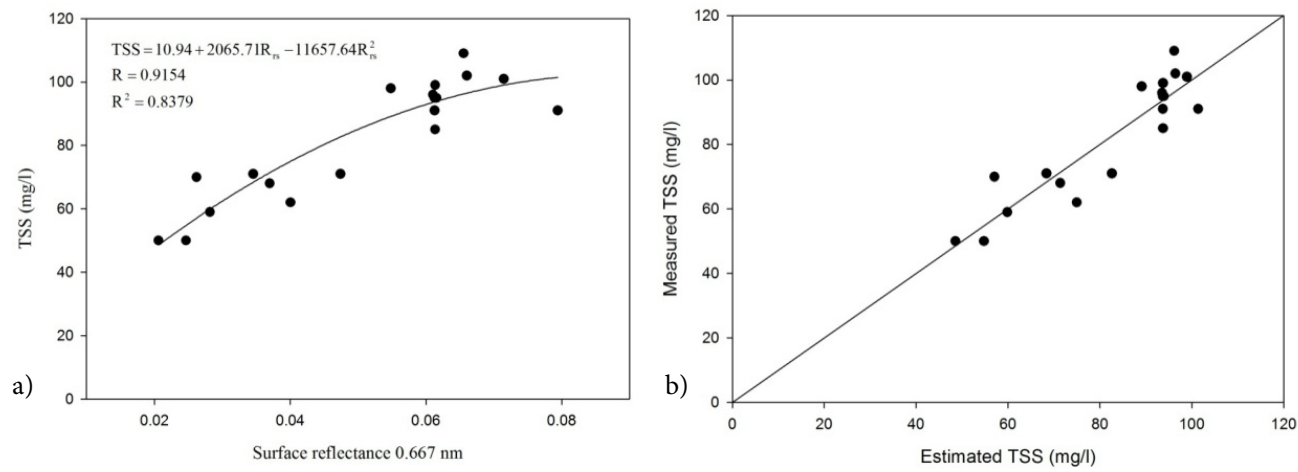

Fig. 3. (a) Measured TSS against surface reflectance of $0.667 \mathrm{~nm}$ for the date of December 8, 2009 and January 29, 2010, (b) Measured TSS against estimated TSS.

Figure 4 shows the TSS map above the study area generated using the developed algorithm. This figure shows that the TSS is higher along the coast and at the south east of the island. Meanwhile, the low TSS is observed at the west of the island.

\section{Conclusion}

A specific algorithm utilizing MODIS Terra $(250 \mathrm{~m})$ surface reflectance product (MOD09) that could map the TSS over the Penang coastal area was developed. A significant relationship (TSS $=-11658 \mathrm{R}_{\mathrm{rs}}{ }^{2}$ $\left.+2065 \mathrm{R}_{\mathrm{rs}}^{2}+10.93 ; \mathrm{R}^{2}=0.838 ; \mathrm{n}=19\right)$ was defined between in-situ TSS (mg/l) and Rrs at $645 \mathrm{~nm}$. This result suggests that the MODIS surface reflectance product could be used to estimate the TSS over this study area.

\section{Acknowledgements}

We would like to thank the UiTM Kuala Terengganu USM and UMT managements for their support and

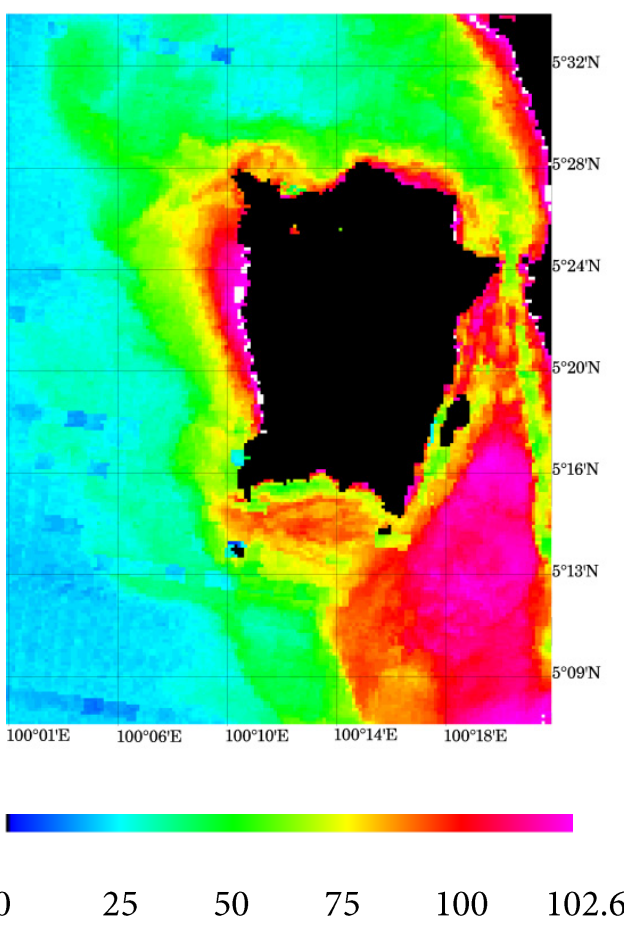

Fig. 4. TSS map generated based on the developed algorithm for the date of 8 December 2009. 
encouragement. Our appreciation also goes to the MODIS team for all the valuable data provided. We thank the reviewers and associate editor for their comments which improved this manuscript.

\section{References}

Chen, Z., Hu, C. \& Muller-Karger F. (2007). Monitoring turbidity in Tampa Bay using MODIS/Aqua 250-m imagery. Remote Sens. Environ., 109(2), 207-220. DOI: 10.1016/j.rse.2006.12.019.

Chu, V.W., Smith, L.C., Rennermalm, A.K., Forster, R.R., Box, J.E. \& Reehy N. (2009). Sediment plume response to surface melting and supraglacial lake drainages on the Greenland ice sheet. Journal of Glaciology, 55(194), 1072-1082. DOI: 10.3189/002214309790794904.

Curran, P.J. \& Novo E.M.M. (1988). The relationship between suspended sediment concentration and remotely sensed spectral radiance: A review. J. Coast. Res., 4, 351-368. http://www.jstor.org/stable/4297423

Doxaran, D., Froidefond, J.M. \& Castaing P. (2003). Remote-sensing reflectance of turbid sediment-dominated waters. Reduction of sediment type variations and changing illumination conditions effects by use of reflectance ratios. Applied Optics, 42(15), 2623-2634. DOI: 10.1364/AO.42.002623.

Hu, C., Chen, Z., Clayton, T.D., Swarzenski, P., Brock, J.C. \& Muller-Karger F.E. (2004). Assessment of estuarine water-quality indicators using MODIS medium-resolution bands: Initial results from Tampa Bay, FL. Remote Sens. Environ., 93(3), 423-441. DOI: 10.1016/j.rse.2004.08.007.

Kotchenova, S.Y., Vermote, E.F., Matarrese, R. \& Klemm Jr, F.J. (2006). Validation of a vector version of the 6S radiative transfer code for atmospheric correction of satellite data. Part I: Path radiance. Applied Optics, 45(26), 6762-6774. DOI: 10.1364/AO.45.006762.

Kuang, R., Zhou, Y. \& Zhu Y. (2011). Monitoring transport of suspended sediment in the Nanhui near shore integrating remote sensing images with hydrodynamic model. In 19th International Conference on Geoinformatics (pp. 1-4). Shanghai: IEEE.

Long, C.M. \& Pavelsky T.M. (2013). Remote sensing of SS concentration and hydrologic connectivity in a complex wetland environment. Remote Sens. Environ., 129, 197-209. DOI: 10.1016/j.rse.2012.10.019.

Miller, R.L. \& McKee B.A. (2004). Using MODIS Terra $250 \mathrm{~m}$ imagery to map concentrations of total suspended matter in coastal waters. Remote Sens. Environ., 93(1-2), 259-266. DOI: 10.1016/j.rse.2004.07.012.

Min, J.-E., Ryu, J.-H., Lee, S. \& Son S. (2012). Monitoring of suspended sediment variation using Landsat and MODIS in the Saemangeum coastal area of Korea. Mar. Pollut. Bull., 64(2), 382-390. DOI: 10.1016/j.marpolbul.2011.10.025.

Moreno-Madrinan, M.J., Al-Hamdan, M.Z., Rickman, D.L. \& Muller-Karger F.E. (2010). Using the surface reflectance MODIS Terra product to estimate turbidity in Tampa Bay, Florida. Remote Sensing, 2(12), 2713-2728. DOI: $10.3390 /$ rs2122713.

Pavelsky, T.M. \& Smith L.C. (2009). Remote sensing of suspended sediment concentration, flow velocity, and lake recharge in the Peace-Athabasca Delta, Canada. Water Resources Research, 45(11). DOI: 10.1029/2008WR007424.

Petus, C., Chust, G., Gohin, F., Doxaran, D., Froidefond, J.M. \& Sagarminaga Y. (2010). Estimating turbidity and total suspended matter in the Adour River plume (South Bay of Biscay) using MODIS 250-m imagery. Continental Shelf Research, 30(5), 379-392. DOI: 10.1016/j.csr.2009.12.007.

Ritchie, J.C., Schiebe, F.R. \& McHenry J.R. (1976). Remote sensing of Ss in surface water. Photogrammetric Engineering and Remote Sensing, 42, 1539-1545.

Rodríguez-Guzmán, V. \& Gilbes-Santaella F. (2009). Using MODIS $250 \mathrm{~m}$ imagery to estimate total suspended sediment in a tropical open bay. International Journal of Systems Applications, Engineering \& Development, 3, 36-44.

Villar, E.R., Martinez, J.-M., Le Texier, M., Guyot, J.-L., Fraizy, P., Meneses, P.R. \& Oliveira E.D. (2013). A study of sediment transport in the Madeira River, Brazil, using MODIS remote-sensing images. Journal of South American Earth Sciences, 44, 45-54. DOI: 10.1016/ j.jsames.2012.11.006.

Wang, F., Zhou, B., Xu, J., Song, L. \& Wang X. (2009). Application of neural network and MODIS 250 m imagery for estimating suspended sediment concentration in Hangzhou Bay, China. Environ. Geol., 56(6), 1093-1101. DOI: $10.1007 / \mathrm{s} 00254-008-1209-0$.

Wang, J. J., \& Lu, X. X. (2010). Estimation of suspended sediment concentrations using Terra MODIS: An example from the Lower Yangtze River, China. Sci. Total Environ., 408(5), 1131-1138. DOI: 10.1016/j.scitotenv.2009.11.057. 